very good at [inducing] cell-mediated immunity, but not so good at inducing an antibody response. We actually think ... that you need both cell-mediated and some degree of humoral immunity," which is induced by the adenoviral

booster.

Unfortunately,

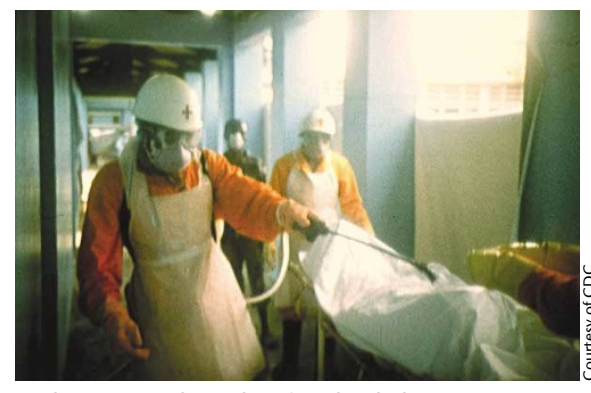

Red Cross workers disinfect body bag is now big. So this makes [the Ebola vaccine] a very attractive way of validating the quality of our vectors and cell lines."

Because the etiology of Ebola is still poorly understood, the availability of a vaccine might also be a boon to public health in the future. "Obviously today Ebola is not a raging epidemic ... on the other hand it takes years to develop a vaccine, so if something should ever break out and we have a product that works, then obviously that's a very good approach for public health," says Nabel.

Before the vaccine can be made available, however, it must gain government approval. Traditional efficacy trials would be both unethical and impractical, so Crucell and NIAID are planning to use an alternative approval process recently introduced by the FDA (see box). Alan Dove, Philadelphia "lots of people

have adenovirus antibodies, which hampers its use [as a vector for vaccine antigens]," according to virology expert Jaap Goudsmit, head of vaccine research at Crucell. To address this problem, Crucell is developing a version of the NIAID Ebola vaccine that will use the rare serotype of adenovirus 35. Less than 5\% of the population has antibodies against this serotype. Crucell has also developed a cell line that will produce replicationdefective adenovirus 35, and is in the process of adapting Nabel's strategy to this platform. Goudsmit estimates that the new vaccine system will be entering nonhuman primate trials at the NIH in 3 to 4 months.

Considering the relative rarity and small size of Ebola outbreaks, the vaccine may appear to be headed for a tiny market. As Goudsmit points out, however, "since 9/11 the world changed dramatically in terms of markets. Did you or did I ever believe there would be a smallpox vaccine market ever again? That market

\section{FDA lowers the bar for biodefense drugs}

Starting this month, the US Food and Drug Administration (FDA) has introduced a shortcut for the approval of drugs and vaccines to treat biological, nuclear and chemical agents that might be used by terrorists. Such products need only prove that they are not toxic to humans rather than that they are effective in humans.

Ordinarily, new drugs and biological therapies must undergo initial trials (phase 1 studies) in humans to assess toxicity, followed two phases of trials (phase 2 and 3 studies) to determine efficacy. Under the new rule, an alternative approval process would allow a company to use preclinical test data showing efficacy in two relevant animals, combined with phase 1 studies only. This approach will be permitted only when human efficacy trials would be impossible or unethical, as in the case of a rare but highly lethal disease that might be used as a biological weapon.

The FDA says that several companies have already expressed an interest in filing applications under the new bypass rule, primarily for biodefense uses of existing antibiotics. Although these drugs are already approved and could technically be prescribed 'off-label' in an emergency, FDA officials argue that having officially sanctioned drugs available will improve public confidence in the face of an emergency.

Some watchdog groups have warned that companies might use the new rule as a shortcut to avoid expensive late-stage clinical trials. A new antibiotic, for example, could be approved to treat anthrax infections without human efficacy trials, and could then be prescribed off-label for more common diseases. Janet Woodcock, director of the FDA's Center for Drug Evaluation and Research, concedes that this is "a theoretical concern," but insists that the FDA retains the ability to stop such abuses if they occur.

A.D.

\title{
New FDA office for gene therapy
}

Mindful of growing public interest and advances in human cell and gene-therapy research, the US Food and Drug Administration (FDA) is to create a new office to oversee the development of these new technologies. From 1 October, cellular, tissue and gene-therapy products will move from offices where they are now regulated into a single new department within the FDA's Center for Biologics Evaluation and Research (CBER), which regulates all products derived from living sources.

"It's an attempt to better group the products and deal with the emerging science in a more consolidated manner," says Mark Elengold, CBER's deputy director for operations. The move "is giving [these fields] their own visibility," he told
Nature Medicine. "Interest in gene therapy was elevated by the Gelsinger tragedy, and we want to show the importance that CBER is placing on these new scientific frontiers."

As yet, there are no FDA-approved genetherapy products on the market. However, Nelson Wivel of the Institute for Human Gene Therapy in Philadelphia, believes the FDA's action "suggests a new office is needed when cutting edge technologies grow and mature, and there is every reason to believe that research activity will continue to increase in these areas." When gene-therapy trials began in 1990, "very few people in the FDA were assigned to this particular oversight," he says. "They borrowed from existing offices and had the capability of calling on as many as 70 people to assist in the review of human gene transfer. But the reality is that the stringency in oversight of human gene transfer has increased significantly over the last two and a half years and the regulatory burden on investigators is considerably more than it used to be," he adds.

The new office does not require Congressional approval or the appropriation of new money or staff, according to the FDA. Those who will need to interact with it are watching the situation closely. "BIO companies are hopeful that these changes will ensure timely, scientifically based reviews of gene-therapy protocols," says Michael Werner, vice president for bioethics of the Biology Industry Organization.

Marlene Cimons, Washington, D.C. 